Pacific Journal of Mathematic 


\title{
WEAK TYPE MULTIPLIERS FOR HANKEL TRANSFORMS
}

\author{
William C. Connett and Alan L. Schwartz
}

The main result of this paper is that weak type multiplier theorems for Jacobi expansions yield weak type multiplier theorems for Hankel transforms.

In recent papers the authors studied multiplier theorems for ultraspherical and Jacobi expansions. An interesting paper of Igari suggested a new approach to multiplier theorems that used asymptotics instead of the elaborate machinery used earlier.

This paper extends the method of Igari to give the first weak type multiplier theorem for Hankel transforms. This extension is important in itself and because this method together with the authors' results for Jacobi multipliers will generalize to the "radial" functions associated with the other compact symmetric spaces.

Let $\left\{P_{n}^{(\alpha, \beta)}(x)\right\}$ be the Jacobi polynomials with indices $(\alpha, \beta)$. The functions $\left\{P_{n}^{(\alpha, \beta)}(\cos \theta)\right\}$ are orthogonal with respect to the measure $d \mu(\theta)=(\sin \theta / 2)^{2 \alpha+1}(\cos \theta / 2)^{2 \beta+1} d \theta$. For measurable $f$ on $[0, \pi]$ define

$$
\|f\|_{p}=\left\{\int_{0}^{\pi}|f(\theta)|^{p} d \mu(\theta)\right\}^{1 / p}
$$

and

$$
f^{\wedge}(n)=\int_{0}^{\pi} f(\theta) P_{n}^{(a, \beta)}(\cos \theta) d \mu(\theta)
$$

so that if

$$
h_{n}^{-1}=\int_{0}^{\pi}\left[P_{n}^{(\alpha, \beta)}(\cos \theta)\right]^{2} d \mu(\theta)
$$

then

$$
f(\theta) \sim \sum_{n=0}^{\infty} f^{\curlywedge}(n) h_{n} P_{n}^{(\alpha, \beta)}(\cos \theta)
$$

where equality holds at least for finite series.

The multiplier transformation defined by the function $\phi(x)$ is denoted by $T_{\phi}$, where at least formally,

$$
T_{\phi} f(\theta) \sim \sum_{0}^{\infty} \phi(n) \hat{f}(n) h_{n} P_{n}^{(\alpha, \beta)}(\cos \theta) .
$$

The operator $T_{\phi}$ is said to be of strong type $p, 1<p<\infty$ if 


$$
\left\|T_{\dot{\phi}}\right\|_{p}=\|\dot{\phi}(n)\|_{p}=\sup \left\|T_{\dot{\phi}} f\right\|_{p} \quad\left(\|f\|_{p}=1\right) .
$$

The operator is said to be of weak type $p$ if.

$$
\left\langle T_{\dot{\phi}}\right\rangle_{p}=\left\langle\langle\dot{\phi}(n)\rangle_{p}=\sup \lambda\left[\mu\left\{x:\left|T_{\dot{\phi}} f(\theta)\right|>\lambda\right\}\right]^{1 / p} \quad\left(\lambda>0,\|f\|_{p}=1\right) .\right.
$$

The same objects of harmonic analysis are also needed for the Hankel transforms. Let $d \eta(x)=x^{2 \alpha+1} d x f_{\alpha}(x)=x^{-\alpha} J_{\alpha}(x)$ and briefly define:

$$
\begin{aligned}
& |g|_{p}=\left(\int_{0}^{\infty}|g(x)|^{p} d \eta(x)\right)^{1 / p}, \\
& \hat{g}(x)=\int_{0}^{\infty} g(y) \mathscr{f}_{\alpha}(x y) d \eta(y)
\end{aligned}
$$

(at least for $g$ continuous with compact support),

$$
g(x) \sim \int_{0}^{\infty} \hat{g}(y) \mathscr{J}_{\alpha}(x y) d \eta(y),
$$$$
U_{\rho} g \sim \int_{0}^{\infty} \phi(y) \hat{g}(y) \mathscr{F}_{\alpha}(x y) d \eta(y),
$$

$\left|U_{\phi}\right|_{p}$ for the strong type $p$ norm of the operator, $\left\langle U_{\dot{\phi}}\right\rangle_{p}$ for the weak type $p$ norm.

The idea of Igari [4] is to transform strong type multiplier theorems for Jacobi expansions into strong type multiplier theorems for Hankel transforms. His result is

Theorem (Igari). Let $\alpha, \beta>-1$ and assume $\dot{\phi}$ is continuous on $(0, \infty)$ except on a null set. If $1 \leqq p<\infty$, then

$$
|\dot{\phi}(x)|_{p}=\liminf _{\varepsilon \rightarrow 0}\|\dot{\phi}(\varepsilon n)\|_{p} .
$$

Igari's techniques are adapted here to prove a similar theorem for weak type multipliers.

THEOREM 1. Under the same hypotheses as above

$$
\langle\dot{\phi}(x)\rangle_{p}=\liminf _{\varepsilon \rightarrow 0}\left\langle\langle\dot{\phi}(\varepsilon n)\rangle_{p} .\right.
$$

The theorem will be proved following a

Lemma. Let $E \subset R$ satisfy $\eta(E)<\infty$ and let $f_{n}(x) \rightarrow f(x)$ a.e. in $E$ as $n \rightarrow \infty$. Then if $s>0$

$$
\eta\{x \in E:|f(x)|>s\} \leqq \liminf _{n \rightarrow \infty}\left\{x \in E:\left|f_{n}(x)\right|>s\right\} .
$$

The lemma can be proved by applying Fatou's lemma to the characteristic function of $\left\{x \in E:\left|f_{n}(x)\right|>s\right\}$. 
Proof of Theorem 1. It will be sufficient to prove the theorem for compactly supported infinitely differentiable functions, so let $g$ be one such with support in $(0, M)$.

Let $g_{\lambda}(\theta)=g(\lambda \theta)$ for $\lambda$ so large that $\lambda \pi>M$, and let

$$
\begin{aligned}
G(\tau, \lambda) & =\sum_{n=0}^{\infty} \phi\left(\frac{n}{\lambda}\right) g_{\hat{\lambda}}(n) P_{n}^{(\alpha, \beta)}\left(\cos \frac{\tau}{\lambda}\right), \\
G^{N}(\tau, \lambda) & =\sum_{n=0}^{N[\lambda]} \phi\left(\frac{n}{\lambda}\right) g_{\hat{\lambda}}(n) P_{n}^{(\alpha, \beta)}\left(\cos \frac{\tau}{\lambda}\right), \\
H^{N}(\tau, \lambda) & =G(\tau, \lambda)-G^{N}(\tau, \lambda), \\
G(\tau) & =\int_{0}^{\infty} \phi(y) g^{\wedge}(y) \mathcal{F}_{\alpha}(\tau y) d \eta(y)=U_{\phi} g(\tau) .
\end{aligned}
$$

A careful reading of Igari's argument shows that there is a constant $B$ independent of $\lambda, N$ and $K$ such that once $\lambda$ is sufficiently large

$$
\int_{0}^{K}\left|H^{N}(\tau, \lambda)\right|^{2} d \eta(\tau) \leqq B / N^{2} .
$$

He shows that $G^{N}(\tau, \lambda)$ converges everywhere to a function $G^{N}(\tau)$ and that a subsequence of $G^{N}(\tau)$ converges a.e. in $(0, \infty)$ to $G(\tau)$.

Let $\varepsilon>0, \delta>0, K>0$, and $s>0$ and define

$$
M_{\lambda}=\left\langle\left\langle\dot{\phi}\left(\frac{n}{\lambda}\right)\right\rangle\right\rangle_{p}^{p}\left\|g_{\lambda}\right\|_{p}^{p} s^{-p} .
$$

If $\phi(n / \lambda)$ defines a weak type $p$ operator on Jacobi series then

$$
\mu\{\dot{\phi}:|G(\lambda \dot{\phi}, \lambda)|>s\} \leqq M_{\lambda} .
$$

Then if $\lambda$ is sufficiently large

$$
\eta\{\tau \leqq K:|G(\tau, \lambda)|>s\} \leqq 2^{2 \alpha+1} \lambda^{2 \alpha+2} M_{\lambda}(1+\varepsilon) .
$$

Let $N^{2}>B / \varepsilon \delta^{2}$ so that relation (1) implies

$$
\eta\left\{\tau \leqq K:\left|H^{N}(\tau, \lambda)\right|>\delta\right\} \leqq \varepsilon,
$$

and $G^{N}(\tau, \lambda)=G(\tau, \lambda)-H^{N}(\tau, \lambda)$ so that

$\left\{\tau \leqq K:\left|G^{N}(\tau, \lambda)\right|>s+\hat{o}\right\} \subset\{\tau \leqq K:|G(\tau, \lambda)|>s\} \cup\{\tau \leqq K:|G(\tau, \lambda)| \leqq s$ and $\left.\left|H^{N}(\tau, \lambda)\right|>\delta\right\}$,

thus

(2) $\quad \eta\left\{\tau \leqq K:\left|G^{N}(\tau, \lambda)\right|>s+\delta\right\} \leqq 2^{2 \alpha+1} \lambda^{2 \alpha+2} M_{\lambda}(1+\varepsilon)+\hat{\varepsilon}$.

Now choose $\lambda_{j} \rightarrow \infty$ such that 


$$
\lim _{j \rightarrow \infty}\left\langle\left\langle\phi\left(\frac{n}{\lambda_{j}}\right)\right\rangle\right\rangle_{p}^{p}=\liminf _{\lambda \rightarrow \infty}\left\langle\left\langle\phi\left(\frac{n}{\lambda}\right)\right\rangle\right\rangle_{p}^{p}
$$

and observe that $\lim _{\lambda \rightarrow \infty} 2^{\alpha+1} \lambda^{2 \alpha+2}\left\|g_{\lambda}\right\|_{p}^{p}=|g|_{p}^{p}$ so

$$
\lim 2^{2 \alpha+1} \lambda_{j}^{2 \alpha+2} M_{\lambda_{j}}=M=\liminf _{\lambda \rightarrow \infty}\left\langle\left\langle\left(\phi \frac{n}{\lambda}\right)\right\rangle\right\rangle_{p}^{p}|g|_{p}^{p} s^{-p}
$$

thus if $\lambda$ is replaced by $\lambda_{j}$ in (2) and then $j$ increased, the lemma implies

$$
\eta\left\{\tau \leqq K:\left|G^{N}(\tau)\right|>s+\delta\right\} \leqq M(1+\varepsilon)+\varepsilon
$$

If $N_{j}$ is now chosen so that $G^{N} j(\tau) \rightarrow G(\tau)$ a.e. in $(0, \infty)$, then relation (3) and the lemma yield

$$
\eta\{\tau \leqq K:|G(\tau)|>s+\delta\} \leqq M(1+\varepsilon)+\varepsilon
$$

Now, first the $\varepsilon$, then the $\delta$, and finally the $K$ can be removed by standard arguments to yield

$$
\eta\left\{\tau:\left|U_{\phi} g(\tau)\right|>s\right\} \leqq \liminf _{\lambda \rightarrow \infty}\left\langle\left\langle\phi\left(\frac{n}{\lambda}\right)\right\rangle\right\rangle_{p}^{p}|g|{ }_{p}^{p} s^{-p}
$$

and the Theorem is proved.

To transfer strong type multiplier theorems from Jacobi series to Hankel transforms Igari's theorem should be used, for weak type results Theorem 1 is the tool; for instance $([\alpha]$ is the greatest integer not exceeding $\alpha$ ).

THEOREM 2. Let $\alpha \geqq \beta>-1 / 2$ and $m=[\alpha]+2$; assume that $\phi$ is $m$ times continuously differentiable in $(0, \infty)$ and let

$$
\left[A_{m}(\phi)\right]^{2}=\sup _{x}|\phi(x)|^{2}+\sup _{M} M^{-1} \int_{M}^{2 M}\left|x^{m} \phi^{(m)}(x)\right|^{2} x^{-1} d x
$$

then $U_{\phi}$ is of weak type 1 and

$$
\left\langle U_{\phi}\right\rangle \leqq C A_{m}(\phi)
$$

where $C$ does not depend on $\phi$.

Proof. Define $\Delta^{0} \phi(n)=\phi(n)$ and $\Delta^{k} \phi(n)=\Delta^{k-1} \phi(n+1)-\Delta^{k} \phi(n)$ for $k=1,2, \cdots$ and let $\phi_{\varepsilon}(x)=\phi(\varepsilon x)$.

It can be shown (see Bonami and Clerc [1], Theorem 4.12) that

$$
\left|\Delta^{m} \phi_{\varepsilon}(n)\right| \leqq \varepsilon^{m-1} \int_{\varepsilon n}^{\varepsilon(n+m)}\left|\phi^{(m)}(x)\right| d x \text {. }
$$

Consequently by the Schwarz inequality and the Mean Value Theorem 
for integrals there is constant $C$ independent of $n$ and $\phi$ such that

$$
\frac{1}{n}\left|n^{m} \Delta^{m} \phi_{s}(n)\right|^{2} \leqq m \int_{\varepsilon n}^{\varepsilon(n+m)}\left|x^{m} \phi^{(m)}(x)\right|^{2} x^{-1} d x
$$

Thus if

$$
\left[B_{m}(\dot{\phi})\right]^{2}=\sup _{n}|\dot{\phi}(n)|^{2}+\sup _{M} M^{-1} \sum_{n=M}^{2 M}\left|n^{m} \Delta^{m} \phi(n)\right|^{2},
$$

then there is a constant $C_{1}$ independent of $\phi$ such that

$$
B_{m}\left(\phi_{\varepsilon}\right) \leqq C_{1} A_{m}(\phi) .
$$

The main result of [3] actually shows that if $\alpha \geqq \beta>-1 / 2$ and $m=[\alpha]+2$ there is a constant $C_{2}$ such that

$$
\left\langle T_{\phi}\right\rangle_{1} \leqq C_{2} B_{m}(\phi) \text {. }
$$

Thus the result follows from Theorem 1 and (4).

\section{REFERENCES}

1. A. Bonami and J.-L. Clerc, Sommes de Cesàro et multiplicateurs des développements en harmoniques sphériques, Trans. Amer. Math. Soc., 183 (1973), 223-263.

2. W. C. Connett and A. L. Schwartz, A multiplier theorem for ultraspherical series, Studia Mathematica, L (1973), 51-70.

3. — A multiplier theorem for Jacobi series, Studia Mathematica, LII (1975), 243-261.

4. S. Igari, On the multipliers of Hankel transform, Tôhoku, Math. J., Second Series, 24 (1972), 201-206.

Received March 15, 1974 and in revised form December 4, 1975. Supported in part by AFOSR Grant 71-2047.

UNIVERSITY OF MisSOURI-ST. LOUIS 



\section{PACIFIC JOURNAL OF MATHEMATICS}

EDITORS

RICHARD ARENS (Managing Editor)

University of California

Los Angeles, California 90024

R. A. BEAUMONT

University of Washington

Seattle, Washington 98105
J. DugundJI

Department of Mathematics

University of Southern California

Los Angeles, California 90007

D. Gilbarg and J. Milgram

Stanford University

Stanford, California 94305

\section{ASSOCIATE EDITORS}

E. F. BECKENBACH

B. H. NeumanN

F. WOLF

K. YosHIDA

\section{SUPPORTING INSTITUTIONS}

UNIVERSITY OF BRITISH COLUMBIA

UNIVERSITY OF SOUTHERN CALIFORNIA

CALIFORNIA INSTITUTE OF TECHNOLOGY

UNIVERSITY OF CALIFORNIA

STANFORD UNIVERSITY

UNIVERSITY OF TOKYO

MONTANA STATE UNIVERSITY

UNIVERSITY OF UTAH

UNIVERSITY OF NEVADA

WASHINGTON STATE UNIVERSITY

NEW MEXICO STATE UNIVERSITY

UNIVERSITY OF WASHINGTON

OREGON STATE UNIVERSITY

UNIVERSITY OF OREGON

OSAKA UNIVERSITY

AMERICAN MATHEMATICAL SOCIETY
NAVAL WEAPONS CENTER

Printed in Japan by International Academic Printing Co., Ltd., Tokyo, Japan 


\section{Pacific Journal of Mathematics}

\section{Vol. 63, No. $1 \quad$ March, 1976}

Ralph Artino, Gevrey classes and hypoelliptic boundary value problems ....... 1

B. Aupetit, Caractérisation spectrale des algèbres de Banach commutatives .... 23

Leon Bernstein, Fundamental units and cycles in the period of real quadratic

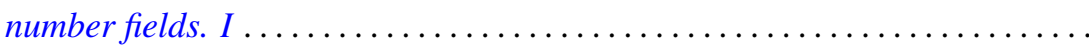

Leon Bernstein, Fundamental units and cycles in the period of real quadratic number fields. II.................................... 63

Robert F. Brown, Fixed points of automorphisms of compact Lie groups ........

Thomas Ashland Chapman, Concordances of noncompact Hilbert cube

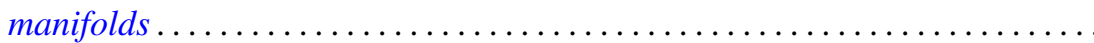

William C. Connett, V and Alan Schwartz, Weak type multipliers for Hankel

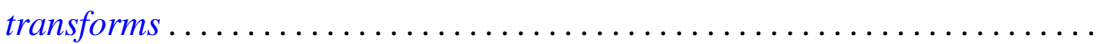

John Wayne Davenport, Multipliers on a Banach algebra with a bounded approximate identity .....................................

Gustave Adam Efroymson, Substitution in Nash functions ................ 137

John Sollion Hsia, Representations by spinor genera ..................

William George Kitto and Daniel Eliot Wulbert, Korovkin approximations in

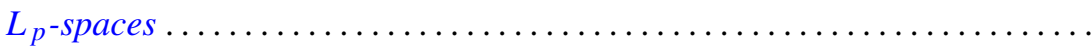

Eric P. Kronstadt, Interpolating sequences for functions satisfying a Lipschitz. condition ...........................................

Gary Douglas Jones and Samuel Murray Rankin, III, Oscillation properties of certain self-adjoint differential equations of the fourth order...

Takaŝi Kusano and Hiroshi Onose, Nonoscillation theorems for differential

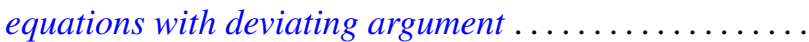

David C. Lantz, Preservation of local properties and chain conditions in commutative group rings. ...

Charles W. Neville, Banach spaces with a restricted Hahn-Banach extension property....

Norman Oler, Spaces of discrete subsets of a locally compact group ...

Robert Olin, Functional relationships between a subnormal operator and its minimal normal extension.

Thomas Thornton Read, Bounds and quantitative comparison theorems for nonoscillatory second order differential equations ...... .

Robert Horace Redfield, Archimedean and basic elements in completely distributive lattice-ordered groups...

Jeffery William Sanders, Weighted Sidon sets

Aaron R. Todd, Continuous linear images of pseudo-complete linear topological spaces.

J. Jerry Uhl, Jr., Norm attaining operators on $L^{1}[0,1]$ and the Radon-Nikodým property.

William Jennings Wickless, Abelian groups in which every endomorphism is a left multiplication. 